Check for updates

Cite this: RSC Adv., 2022, 12, 631

Received 26th September 2021 Accepted 14th December 2021

DOI: $10.1039 / d 1 r a 07189 k$

rsc.li/rsc-advances

\section{Application of double-pulse laser-induced breakdown spectroscopy (DP-LIBS), Fourier transform infrared micro-spectroscopy and Raman microscopy for the characterization of copper- sulfides}

\author{
Constantinos Varotsis, ${ }^{*}$ Charalampos Tselios, (D) Konstantinos A. Yiannakkos, \\ Charalampos Andreou, Marios Papageorgiou (D) and Antonis Nicolaides (D)
}

\begin{abstract}
The combined application of the structure sensitive techniques Fourier transform infrared $\mu$-spectroscopy and Raman microscopy in conjunction with different approaches of laser-induced breakdown spectroscopy (LIBS) including the two-color double pulse (DP-LIBS) have been applied towards the characterization of whole ore copper-sulfide minerals. Discrete information from the surface of the whole ore minerals that lead to the establishment of infrared marker bands and from the surface of bioleached samples that allow the monitoring of jarosite and biofilm formation are provided by FTIR mapping experiments. Raman data can provide information related to the type of the mineral and of the secondary minerals formed on the surface of the ore. Of the four different LIBS approaches applied towards the characterization of the composition of the whole ore minerals, the DP-LIBS shows the highest sensitivity with increasing signals for both the Fe and Cu metals in the whole ore samples.
\end{abstract}

\section{Introduction}

The mineralogy, mineral chemistry, geological occurrences, and mineral processing techniques of sulfide minerals have been well investigated and applied because of their economical and environmentally safe significance. ${ }^{\mathbf{1 - 4 9}}$ There is consensus, that applications of advanced spectroscopic techniques are necessary for the characterization of minerals from whole ores. ${ }^{3,4,47}$ In the field of bio-hydrometallurgy the determination of the chemical and structural properties of minerals prior to microorganism-mineral interactions is the determinant factor towards the successful metal(s) extraction. ${ }^{3,4}$ The technique it is simple and has been successfully applied for $\mathrm{Cu}$ extraction from sulfide minerals. ${ }^{1-4}$ Novel techniques have been employed to monitor metal extraction from low-grade sulfide ores and for probing the bacterial activities of acidophilic iron- and sulfuroxidizing microorganisms towards elimination of $\mathrm{Fe}^{3+}$ hydroxysulfates such as jarosite. ${ }^{\mathbf{1 3 - 3 0}}$ A great number of studies have agreed in that jarosite precipitation is linked to the passivation of chalcopyrite. There is consensus that the mechanisms involved in biohydrometallurgy require substantial further research and thus, new methods towards the fast and accurate identification of the metal content of whole ore minerals and the mechanisms involved in their extraction should be further

Department of Chemical Engineering, Cyprus University of Technology, Eirinis 95, Limassol, 3041, Cyprus. E-mail: c.varotsis@cut.ac.cy; Fax: +357 25002802 explored. Laser-induced breakdown spectroscopy (LIBS), Raman and FTIR techniques are attractive tools in the areas of environmental monitoring, geology and in the field of mining. In the mining industry all three techniques have been applied in order to develop sensing technologies that can be used as robust and rugged tools for the positive identification of heavy metals in real-time and because they are cost effective and easier for application (Fig. 1).

The (bio)-chemical oxidation of chalcopyrite $\left[\mathrm{CuFeS}_{2}\right]$, chalcocite $\left[\mathrm{Cu}_{2} \mathrm{~S}\right]$, idaite $\left[\mathrm{Cu}_{5} \mathrm{FeS}_{6}\right]$ and bornite $\left[\mathrm{Cu}_{5} \mathrm{FeS}_{4}\right]$ by microorganisms has been a subject of extensive research for the last twenty years. ${ }^{1-49}$ Oxidation of the most important $\mathrm{Cu}$ sulfides (covellite, chalcocite and chalcopyrite) is presented in eqn (1)-(3):

$$
\mathrm{CuS}(\mathrm{s})+\mathrm{Fe}_{2}\left(\mathrm{SO}_{4}\right)_{3}(\mathrm{aq}) \rightarrow \mathrm{CuSO}_{4}(\mathrm{aq})+\mathrm{S}(\mathrm{s})+2 \mathrm{FeSO}_{4}(\mathrm{aq}) \text { (1) }
$$

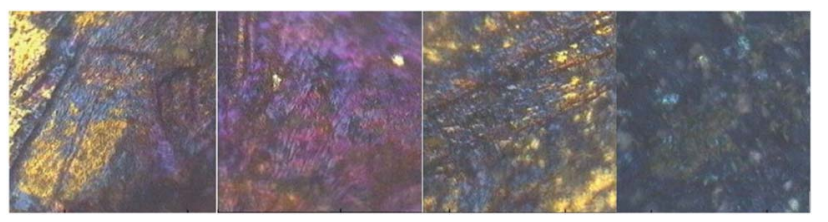

Fig. 1 Whole ore copper sulfide minerals with characteristic color layers. Chalcopyrite: golden yellow; idaite: harvest gold; bornite: purple; covellite-chalcocite: blue-navy. The images were taken by a HYPERION 2000 microscope. 
$\mathrm{Cu}_{2} \mathrm{~S}(\mathrm{~s})+\mathrm{Fe}_{2}\left(\mathrm{SO}_{4}\right)_{3}(\mathrm{aq}) \rightarrow 2 \mathrm{CuSO}_{4}(\mathrm{aq})+\mathrm{S}(\mathrm{s})+4 \mathrm{FeSO}_{4}(\mathrm{aq})(2)$

$$
\mathrm{CuFeS}_{2}(\mathrm{~s})+\mathrm{Fe}_{2}\left(\mathrm{SO}_{4}\right)_{3}(\mathrm{aq}) \rightarrow \mathrm{CuSO}_{4}(\mathrm{aq})+2 \mathrm{~S}(\mathrm{~s})+
$$

$5 \mathrm{FeSO}_{4}(\mathrm{aq})$

The passivation of chalcopyrite $\left[\mathrm{CuFeS}_{2}\right]$ is a major problem that reduces the yields from leaching and bioleaching. Passivation involves the formation of a layer of secondary minerals on minerals surface which creates a diffusion barrier to fluxes of reactants and products. We have presented Raman and FTIR evidence toward identification of secondary minerals formed during the passivation of $\mathrm{Cu}$ sulfide minerals in the presence of iron and sulphur-oxidizing bacteria isolated from the mines of HCM. ${ }^{3,4,47}$ The major detectable species in the passivation layer are $\mathrm{CuS}$ and elemental sulphur-S ${ }^{0}$. In addition, the surface dynamics of the formation of micro-macro-colonies with variable cell density and the formation of extracellular polymeric substances toward the elucidation of the sulfur bio-oxidation and biofilm format has been reported. The Raman and FTIR data indicated the $\mathrm{S}_{n}{ }^{2-} / \mathrm{S}^{0}$ consumption modification during biofilm evolution. This way, the role of the cell density in the primary events with the presence of $\mathrm{S}^{0}$ was determined and whether the presence of refractory sulfur species on the surface of the mineral affects biofilm formation. The constituents of EPS of the biofilms was also evaluated. Essential elucidation of the mineralogy of $\left[\mathrm{CuFeS}_{2}\right]$ and its transformation is necessary to understand the mechanism of passivation. The main objective of our research has been the characterization of the mineral phases generated in the bioleaching processes and gain insights in transformation processes of these phases, as a support to understand its influence on the passivation of the process.

FTIR spectroscopy is an analytical spectroscopic method for studying subtle changes in secondary structure of proteins as it allows the analysis of chemical bonds. ${ }^{3,4,47,50-53}$ Monitoring the conformations changes of protein structures may originate from interactions with other biomaterials or inorganic matter. Such interactions are of high relevance in various physiological cellular processes such as cellular attachment in sulfide mineral surfaces during bioleaching processing. ${ }^{47}$ Laser Raman micro spectroscopy has been applied as a technique for the characterization of biomaterials and secondary minerals formed during the chalcopyrite leaching. ${ }^{54-56}$ This way, distinct information from a large sample area of a heterogeneous sample is feasible. We have recently applied these microspectroscopic approaches for probing the formation of secondary minerals from the surface of bioleached Cu-containing minerals and also establish the vibrational marker bands for monitoring the formation of different types of jarosite and of EPS.

LIBS has the capability of rapid and in situ analysis with no sample preparation required which allows measurements in the laboratory and in the field including studies in geological areas. $^{57-62}$ The specific application of concurrent time resolved LIBS-Raman for monitoring the origin of mining tailings provide a new state-of-the-art approach in the field. This is important at both the level of the industrial heap bioleaching process, and more generally for the scientific community because the time-resolved approach increases the limit of detection. This is a novel approach in heap bioleaching and although it has been used by scientists in other field of biotechnology in the copper bioleaching process has not been applied, yet. LIBS employs a high-power laser beam focused onto a sample to create a plasma. A short duration laser pulse strikes the sample increasing the temperature of the sample causing the matter in the spark to be vaporized, reduced to its atomic species, and then electronically excited. Emission lines at discrete wavelengths that characterize the elements present are then resolved spectrally and temporally with a spectrometer covering part or all of the ultraviolet through near infrared range. Each element emits at different wavelengths and therefore the elements contained within a material can be characterized from the spectral peaks present. The peak intensities provide a quantitative description of the material.

The combination of LIBS-Raman and FTIR mapping techniques provides significant advantage in monitoring chemicalprocesses and composition because the molecular information is added to the atomic data and a more complete description is available. LIBS is more sensitive in the detection of metal elements than nonmetals. The Raman bands of some materials have well known characterized vibrational bands which can specifically identify the molecular composition or their crystals and crystal form. No reports with respect the applicability of all three techniques in the field of bio-hydrometallurgy are available. In this short review, we have extended our time-resolved vibrational approach of Raman and step-scan FTIR on biomolecules and present new results based on different approaches of LIBS to demonstrate the importance of the techniques towards our understanding the bio-hydrometallurgy dynamics of whole ore sulfide minerals.

\section{Experimental}

\subsection{Bioleaching experiments}

Samples of copper sulfide minerals were collected from the mines of HCM in Skouriotissa, Cyprus, and for the bioleaching experiments the samples were placed in test tubes with the corresponding growth medium and a proper inoculation of cell suspensions of Acidithiobacillus ferrooxidans (DSM 14882) and Erythrobacter Longus (DSM 6997). The bacteria were purchase from Deutsche Sammlung von Mikroorganismen und Zellkulturem (DSMZ). The bacteria were cultured in Difco marine broth 2216 medium at $28^{\circ} \mathrm{C}$. Bio-interaction experiments in the tubes were carried out under aseptic conditions in a water bath at $37^{\circ} \mathrm{C}$ using recirculating solutions. The test tubes were fitted with rubber stoppers and the suspension (growth medium and cells) was recirculated by a pump from Cole-Parmer through inlet/outlet tubes. The test tubes were placed in a custom-made plexiglass apparatus of 60 positions.,

\subsection{FTIR microspectroscopy}

Fourier transform infrared microspectroscopy ( $\mu$-FTIR) was applied at defined time intervals to monitor the conformational changes in amide I during the biofilm formation and jarosite 
formation on the copper sulfide ores. Spectra were collected with a Tensor 27 Fourier transform infrared spectrometer and a coupled HYPE-RION 2000 microscope. The microscope was equipped with a liquid nitrogen cooled $\mathrm{HgCdTe}$ (MCT) detector and a motorized $x y$ sample stage. Spectra acquisitions were obtained at a resolution of $4 \mathrm{~cm}^{-1}$ over the spectral range 7500$600 \mathrm{~cm}^{-1}$ using a co-addition of 32 scans and a defined optical field of $100 \times 100 \mu \mathrm{m}$ by glass slide. Spectra were recorded in reflectance mode using a $15 \times$ or $36 \times$ IR objective and processed through Opus 7.0 (Bruker) and OriginPro 9.0 softwares. Attenuated total reflection was used to obtain infrared spectra of extracellular polymeric substances in film form. Spectra were collected using an ATR-Germanium plate (Pike Technologies) and the FTIR Tensor 27 (Bruker) spectrometer equipped with a deuterated triglyceride sulfate (DTGS) detector. The spectra were collected in the 900-4000 $\mathrm{cm}^{-1}$ spectral range with a resolution of $4 \mathrm{~cm}^{-1}$ and 100 co-exposures. Prior to each sample measurement, a back-ground spectrum was collected. The OPUS 7/IR (Bruker) software package was used to acquire and process the FTIR spectra. Fig. 2 depicts the sample stage used for the experiments of the whole ore copper sulfide minerals.

\subsection{Raman microspectroscopy}

Raman data were collected by a LabRAM from HORIBA Jobin Yvon equipped with a CCD detector. It is equipped with an Olympus BX41 microscope 50X. The $442 \mathrm{~nm}$ excitation laser beam was provided by a Helium-Cadmium laser. The laser power incident on the sample was $20 \mathrm{~mW}$ and the accumulation time 15-20 min for each spectrum.

\subsection{Two color double pulse LIBS}

Fig. 3 shows the experimental set-up for the time-resolved LIBS that can be used as a single pulse (1064 or $532 \mathrm{~nm}$ ), dual pulse (collinear 1064 and $532 \mathrm{~nm}$ ) and in a time-resolved approach. The present study investigates the single and the collinear twocolor double-pulse LIBS (DP-LIBS) configuration using $1064 \mathrm{~nm}$ from a Quantel Brilliant nanosecond laser (7 ns pulse) operating at $10 \mathrm{~Hz}$ or $50 \mathrm{~Hz}$ and the $532 \mathrm{~nm}$ pulse from a Minilite Continuum laser (7 ns pulse) operating at 1-15 Hz. For dual

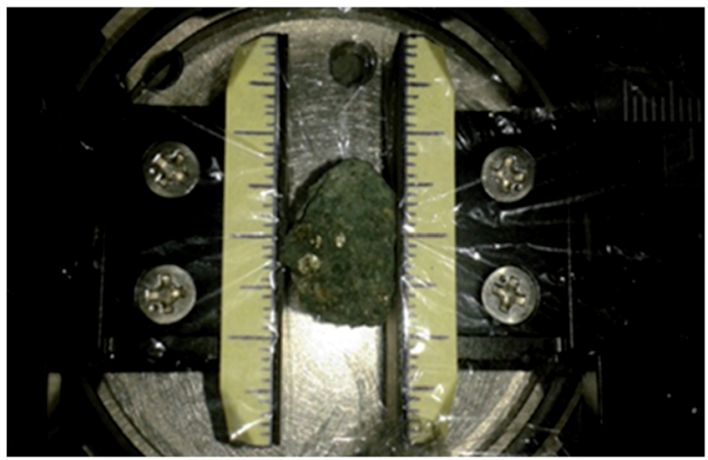

Fig. 2 Sample stage used for the experiments of the whole ore samples.

\section{Time-Resolved LIBS}

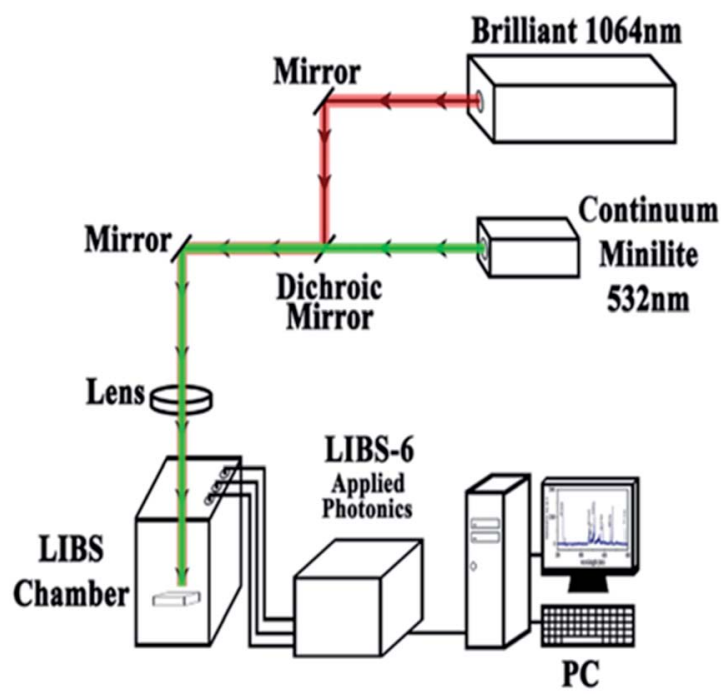

Fig. 3 Experimental set up for the two color (1064 and $532 \mathrm{~nm}$ ) DBLIBS. The experimental set-up consists of two Nd:YAG lasers Brilliant (Quantel) operating at $10 \mathrm{~Hz}$ and Minilite (Con-tinuum) operating at 1$15 \mathrm{HZ}$ and the LIBS-6 from applied photonics. In the time-resolved DP-LIBS a delay generator (Stanford Instruments Model DG535) controls the triggering and timing of the lasers.

pulse experiments a delay generator (Stanford Instruments Model DG535) will control the triggering and timing of the lasers. We will utilize the double pulse technique with delay time $t_{\mathrm{d}}=1.5 \mathrm{~ns}$ which is ideal to detect and visualize the distribution of the desired chemical element on the sample surface. The LIBS laser beam that was used for the experiments reported in this paper was the Brilliant from Quantel at a wavelength of $1064 \mathrm{~nm}$. Every spectrum was taken with pulsed energy of $30 \mathrm{~mJ}$ at a repetition rate of $10 \mathrm{~Hz}$. The internal delay time was $2.51 \mu$ s and the integration time $0.030 \mathrm{~ms}$. In addition, the Minilite laser was used from continuum at a wavelength of $532 \mathrm{~nm}$ and at a rep rate of either $1 \mathrm{~Hz}$ or $10 \mathrm{~Hz}$ and pulsed energy of $8 \mathrm{~mJ}$. A spectrometer from applied photonics was used to analyze plasma emission.

\section{Results and discussion}

We have performed Raman, FTIR and LIBS on different types of whole ore copper sulfide minerals. Raman spectroscopy is a powerful structure sensitive technique for identifying species on the surfaces of the whole copper sulfide minerals. A number of sulphides exist in the $\mathrm{Cu} / \mathrm{Fe} / \mathrm{S}$ system that contain $\mathrm{S}-\mathrm{S}$ bonds including pyrite, $\mathrm{FeS}_{2}$ which displays a $\mathrm{S}-\mathrm{S}$ stretching vibration at $380 \mathrm{~cm}^{-1}$ and is significantly different from that present in the $\mathrm{Cu} / \mathrm{Fe} / \mathrm{S}$ system that contain $\mathrm{S}-\mathrm{S}$ bonds and has been observed at 464-467 $\mathrm{cm}^{-1} \cdot{ }^{34-47}$ Thus, CuS can be distinguished from other phases that contain S-S bonds, and the position of the S-S stretch provides information on the Fe content of the phase. Elemental sulphur and polysulfides also contain S-S linkages and display sharp S-S stretch bands in the Raman 
spectra at $470 \mathrm{~cm}^{-1}$. This band overlaps with that from CuS and bornite $\left[\mathrm{Cu}_{5} \mathrm{FeS}_{4}\right]$ bornite when both species are present on the same region of the surface. Obviously, covellite and bornite cannot be distinguished from sulphur from this band alone. Sulphur also displays an equally strong band from $\mathrm{S}-\mathrm{S}-\mathrm{S}$ chain bending at $215 \mathrm{~cm}^{-1}$ which is not found in covellite and the ratio of the intensities of the two bands can potentially be used to distinguish the two phases.

The Raman spectrum of chalcopyrite is characterized by a weak band at $293 \mathrm{~cm}^{-1}$ which has been assigned to the symmetric anion $\mathrm{A} 1$ mode. ${ }^{21,22}$ The $v(\mathrm{Cu}-\mathrm{S})$ stretching vibration in the $\mathrm{Cu} / \mathrm{Fe} / \mathrm{S}$ systems, bornite, chalcocite and covellite is located in the $470-474 \mathrm{~cm}^{-1}$. Therefore, it is difficult to distinguish bornite, chalcocite and covellite based on the $v(\mathrm{Cu}-\mathrm{S})$. However, there are easily distinguishable by colour. The $v(\mathrm{Cu}-\mathrm{S})$ of $\mathrm{Cu}_{2} \mathrm{~S}$ which belongs to a $\mathrm{Cu} / \mathrm{S}$ system is observed at $470 \mathrm{~cm}^{-1}$ providing new information on the iron content in the $\mathrm{Cu} / \mathrm{Fe} / \mathrm{S}$ system. The $v(\mathrm{Cu}-\mathrm{S})$ of chalcocite was recently reported for the first time. ${ }^{4}$ It was previously reported that $\mathrm{CuS}_{2}$ has no Raman peaks between 200 and $500 \mathrm{~cm}^{-1}$ and thus its formation was suggested without providing evidence for its formation. ${ }^{21,22}$ The Raman peak at $474 \mathrm{~cm}^{-1}$ is the $v(\mathrm{Cu}-\mathrm{S})$, in agreement with previous results. $^{21,22}$ The Raman spectra including the images can provide the necessary information for characterization of surface species/phases and spatial variations in composition of the bioleaching of chalcopyrite. Furthermore, information regarding the formation of the passivation layers in all of the above mentioned $\mathrm{Cu} / \mathrm{Fe} / \mathrm{S}$ and $\mathrm{Cu} / \mathrm{S}$ systems is feasible. Fig. 4 spectra A-B depicts the $442 \mathrm{~nm}$ excitation Raman spectra of quartz (spectrum A), and bornite (spectrum) and in the inset the FTIR spectra of chalcopyrite (spectrum A) and idaite (spectrum B). The image of the sample (spectrum A) has some colourcharacteristics of that of either covellite and or chalcocite. However, the Raman spectrum shows an intense band at

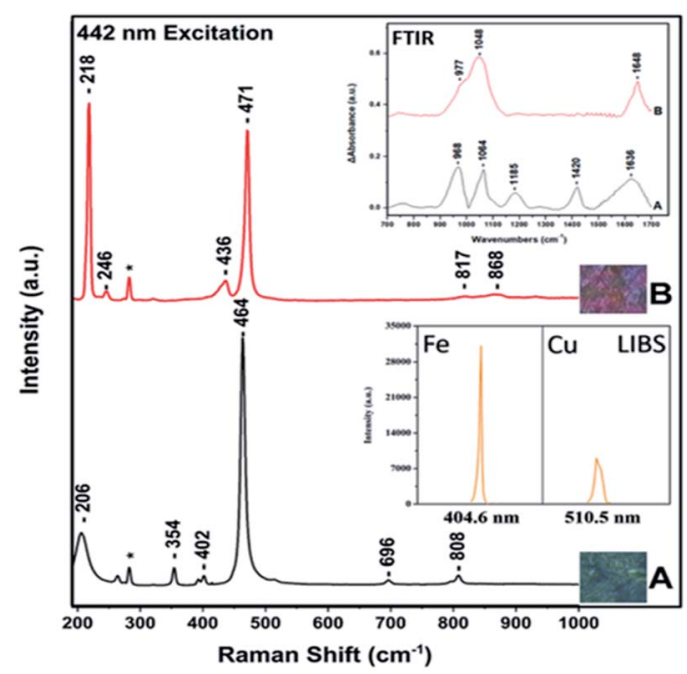

Fig. 4442 nm Raman spectra of quartz (spectrum A) and bornite $\mathrm{Cu}_{5} \mathrm{FeS}_{4}$ (spectrum B). Ex-perimental conditions are the same as previously reported $(3,4)$. The inset shows the FTIR spectra of $(A)$ chalcopyrite (B) idaite.
$464 \mathrm{~cm}^{-1}$ (A1 mode) and a moderate at $206 \mathrm{~cm}^{-1}$ which both have been reported to originate from quartz. Spectrum B is similar to that we have reported. ${ }^{3,4}$ As observed in the inset spectrum A, which corresponds to chalcopyrite, the stronger signals could correspond to ferric sulfate at $1064 \mathrm{~cm}^{-1}$, and hydrated ferrous sulfate and copper sulfate at $968 \mathrm{~cm}^{-1}$, ferrous sulfate and hydrated ferric sulfate $\left(1185 \mathrm{~cm}^{-1}\right)$. The broad band at $1636 \mathrm{~cm}^{-1}$ is due to $\mathrm{H}-\mathrm{O}-\mathrm{H}$. Spectrum $\mathrm{B}$ which corresponds to idaite has characteristic bands of $977 \mathrm{~cm}^{-1}$ due to hydrated ferrous sulfate and copper sulfate at $968 \mathrm{~cm}^{-1}$ and at $1048 \mathrm{~cm}^{-1}$ due to ferric sulfates. For the $\mathrm{FeS}_{2}$ samples, the main peaks correspond to hydroxyl ferric sulfate $\left(1230 \mathrm{~cm}^{-1}\right)$, ferric sulfate $\left(1176 \mathrm{~cm}^{-1}\right)$, ferric sulfate cluster $\left(1140 \mathrm{~cm}^{-1}\right)$, ferrous sulfate $\left(1089 \mathrm{~cm}^{-1}\right)$ and hydrated ferric sulfate $\left(1020 \mathrm{~cm}^{-1}\right)$. Nonhydrated ferric sulfates possess strong vibrations in the $1200 \mathrm{~cm}^{-1}$ range, and, as observed in Fig. 6, there is almost no existence of these vibrations in the case of idaite but in the case of chalcopyrite there is a band at $1185 \mathrm{~cm}^{-1}$.

Fig. 5 shows the Raman and FTIR spectrum of bornite $\left[\mathrm{Cu}_{5} \mathrm{FeS}_{4}\right]$ in a period of ten months of bioleaching by A. Ferrooxidans. In a recent paper the detailed analysis and assignment of all the vibrations present in the Raman and FTIR data
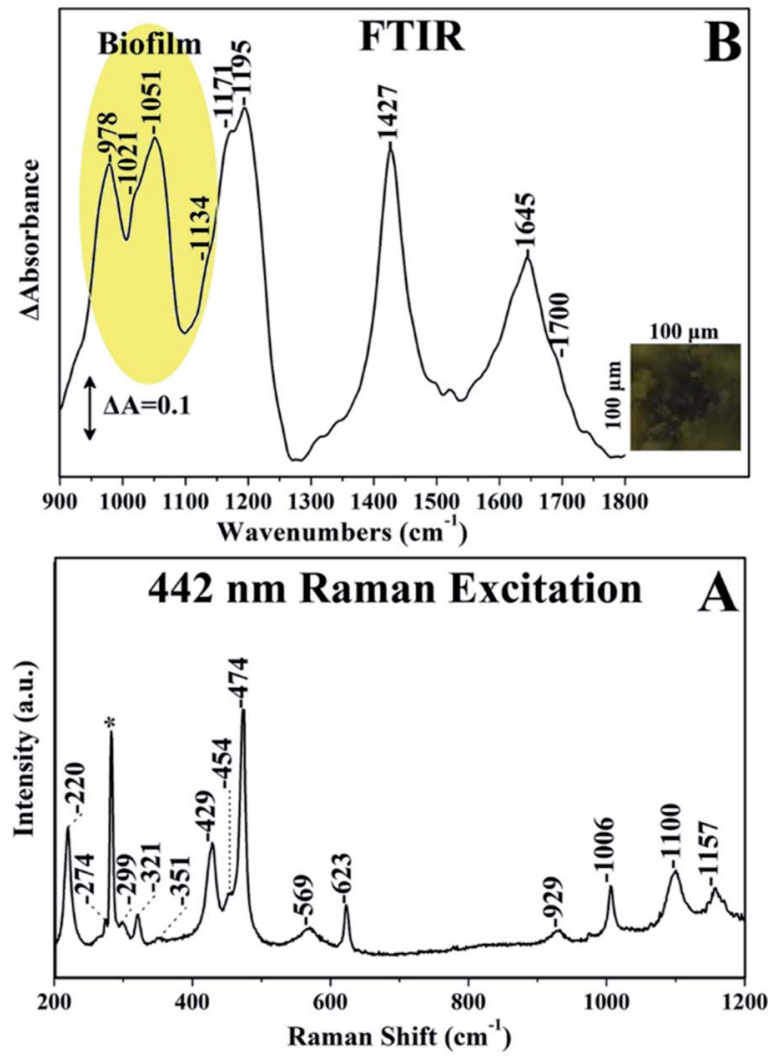

Fig. 5 Panel A: $442 \mathrm{~nm}$ Raman excitation spectra of bioleached bornite by $A$. The laser power incident on the sample was $20 \mathrm{~mW}$ and the accumulation time was 15 minutes. Panel $B$ : collective image of surface of bioleached bornite $\left[\mathrm{Cu}_{5} \mathrm{FeS}_{4}\right]$ by Acidithiobacillus ferrooxidans and the FTIR spectra collected form the surface of the mineral. The area of infrared fingerprint is $0.01 \mathrm{~mm}^{2}$ with spectra resolution $4 \mathrm{~cm}^{-1} .47$ 


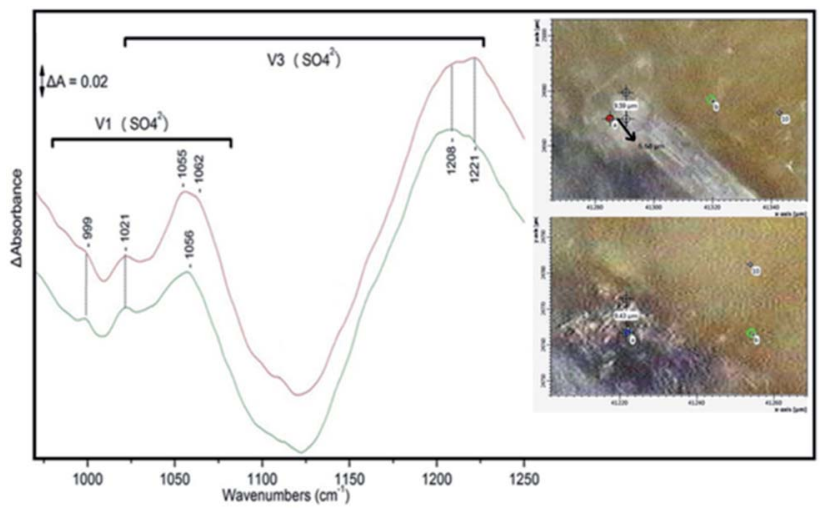

Fig. 6 The FTIR and the $100 \times 100 \mathrm{~mm}$ FTIR spectra of chalcopyrite which showed changes of the ore over a six-month bioleached time period have been reported by our group.

were reported..$^{3,4,47}$ The $\mathrm{K}^{+}$and $\mathrm{NH}_{4}{ }^{+}$vibrations of jarosite is the $\nu_{3}\left(\mathrm{SO}_{4}{ }^{2-}\right)$ vibration which is located observed at $1100 \mathrm{~cm}^{-1}$ in the spectra of $\mathrm{K}^{+}$-jarosite and at $1091 \mathrm{~cm}^{-1}$ in the spectrum of $\mathrm{NH}_{4}{ }^{+}$-jarosite ${ }^{3}$ and the band at $474 \mathrm{~cm}^{-1}$ was assigned to $\nu(\mathrm{Cu}-$ S) of covellite. ${ }^{47}$ Elemental sulphur and polysulfides contain S-S linkages and display the $\nu(\mathrm{S}-\mathrm{S})$ and $\delta(\mathrm{S}-\mathrm{S}-\mathrm{S})$ which are characterized by equally strong intensities at 470 at $215 \mathrm{~cm}^{-1}$, respectively. The intensity of the $\nu(\mathrm{S}-\mathrm{S}) / \delta(\mathrm{S}-\mathrm{S}-\mathrm{S})$ ratio at $470 / 215$ $=1$ has been applied used to distinguish the elemental sulphur from the other $\mathrm{S}-\mathrm{S}$ and $\mathrm{Cu}-\mathrm{S}$ bond containing species. ${ }^{3,4}$ In addition, all bands attributed to $\mathrm{K}^{+}$-jarosite including the $\nu(\mathrm{Fe}-$ O) at $429 \mathrm{~cm}^{-1}$ are present. ${ }^{47}$

In the FTIR spectra shown in Fig. 5B all the characteristic bands were assigned to amide I $\left(1645 \mathrm{~cm}^{-1}\right)$, to biofilm formation $\left(978-1134 \mathrm{~cm}^{-1}\right)$ and near $1700 \mathrm{~cm}^{-1}$ to the $v(\mathrm{C}=\mathrm{O})$ vibration of the O-acetyl ester bond of free EPS. The bands at 978, 1021 and $1051 \mathrm{~cm}^{-1}$ are due to carbohydrates and at $1134 \mathrm{~cm}^{-1}$ due to $\mathrm{P}=\mathrm{O}$ and the band at $1171 \mathrm{~cm}^{-1}$ was attributed to $\mathrm{Fe}-\mathrm{O}-\mathrm{P}$ bonds. ${ }^{47}$

Potassium Jarosite $\left[\mathrm{KFe}_{3}\left(\mathrm{SO}_{4}\right)_{2}(\mathrm{OH})_{6}\right]$ is common in acidic and sulfate-rich environments. Jarosite typically is formed in ferric rich, acidic $(\mathrm{pH}<3)$ oxic environments and readily breaks down when removed from its stability region by presumably converting to iron(III) oxide or oxyhydroxide phases. $\mathrm{K}^{+}$-jarosite converts to goethite through the following reaction ${ }^{43}$

$$
\begin{array}{r}
\mathrm{KFe}_{3}\left(\mathrm{SO}_{4}\right)_{2}(\mathrm{OH})_{6}(\mathrm{~s}) \leftrightarrow \\
2 \mathrm{SO}_{4}{ }^{2-}(\mathrm{aq})+3 \mathrm{FeO}(\mathrm{OH}) \text { Geothite }+\mathrm{K}^{+}(\mathrm{aq})
\end{array}
$$

However, the mechanisms of this reaction, and the specific products formed have not been studied in detail. This knowledge is of profound importance in predicting geochemical reactions in metallurgical environments. Monitoring the fate of $\mathrm{K}, \mathrm{SO}_{4}{ }^{2-}$ and $\mathrm{Fe}$ during $\mathrm{K}$-jarosite dissolution will aid in describing the geochemical cycling of these element in ARD/ AMD systems. Jarosite which is formed subsequently to the formation of goethite has a low solubility and high stability $\left(K_{\mathrm{sp}}\right.$ $=10^{-11}$ and $G_{0}^{f}=-3309.8 \mathrm{~kJ} \mathrm{~mol}^{-1}$ ). The formation of jarosite is also related to the redox potential of the solution. Redox potential higher than $400 \mathrm{mV}$ favour $\mathrm{Fe}^{3+}$ precipitation. It has been demonstrated that Acidithiobacillus ferrooxidans is forming jarosite group minerals de-pending on the temperature, $\mathrm{pH}$, aging time and dissolved oxygen (OD) levels. ${ }^{10,18}$ From the dissolution rates we can determine if K-jarosite can survive as long as the $\mathrm{NH}_{4}{ }^{+}$-jarosite. Jarosite in biological environments is formed from schwertmannite $\mathrm{Fe}_{8} \mathrm{O}_{8}(\mathrm{OH})_{6} \mathrm{SO}_{4}$ which is substituted with $\mathrm{NH}_{4}{ }^{+} / \mathrm{H}_{3} \mathrm{O}^{+}$when the temperature is increased from 36 to $45^{\circ} \mathrm{C}$. The required cations can be acquired from dissolution of minerals and from acid-neutralizing additives.

Electron scanning microscopy (SEM) images of unleached and leached chalcopyrite have been reported but it is difficult to differentiate $\mathrm{K}^{+}$-from $\mathrm{NH}_{4}{ }^{+}$-jarosite because jarosite morphology depends on the experimental conditions and the shape which is round for $\mathrm{K}^{+}$-jarosite and cubic for the $\mathrm{NH}_{4}{ }^{+}$jarosite and size cannot be used as a tool. On the same line are the X-ray diffraction patterns which are difficult to differentiate on the basis of $d$-spacing. The formation of $\mathrm{K}^{+}$and $\mathrm{NH}_{4}{ }_{4}$-jarosite has been observed in $35-100 \mathrm{~mm}$ size grains of high-grade chalcopyrite after bioleaching in laboratory studies but never observed in natural ore samples under experimental conditions that mimic chalcopyrite heap bioleaching processes at $35^{\circ} \mathrm{C}$. In addition, the communities of microorganisms (biofilms) which are embedded in a hydrogen-like matrix formed by EPS on chalcopyrite surfaces during the bioleaching process contributing in the biosynthesis of jarosite have not been reported yet. An overall equation for the dihydroxylation, dehydration and deammoniation of $\mathrm{NH}_{4}{ }^{+}$-jarosite in the $300-400{ }^{\circ} \mathrm{C}$ range is given by

$$
2 \mathrm{NH}_{4} \mathrm{Fe}_{3}\left(\mathrm{SO}_{4}\right)_{2}(\mathrm{OH})_{6} \rightarrow 7 \mathrm{H}_{2} \mathrm{O}+2 \mathrm{NH}_{3}+2 \mathrm{Fe}_{3} \mathrm{O}_{2.5}\left(\mathrm{SO}_{4}\right)_{2}
$$

Fig. 6 shows the FTIR spectra and images of a bioleached area of covellite with $A$. ferroxidans in a two month period. The bottom spectrum is that of the first month with characteristic bands due to $v_{1}$ and $v_{3}$ of $\left(\mathrm{SO}_{4}\right)$. In a time-period of two months the top spectrum shows variation in the frequencies of $v_{1}$ and $v_{3}$ demonstrating the real time changes that take time on the surface of the bioleached ore. Comparison of the images also suggest the formation of biofilm on the surface. This way we can monitor the kinetics of biofilm formation and gain knowledge of the dynamics of the surface proper-ties in the presence of microorganisms and also the time period the microorganisms are active on the surface of the ore. A detailed description of the kinetics involved in the formation of biofilm and jarosite is described in references.

Although sulfide minerals are important sources of metals, they are potential sources of pollution. The release of sulfur through the weathering of sulfides in natural rocks or in mine wastes generates sulfuric acid, resulting in acid rock drainage or acid mine drainage (AMD). Sulfurous fumes are produced by smelting sulfide ores which react to form acid rain. Metal sulfides are very important in Marine geosciences. Therefore, it is intriguing to gain knowledge on the interactions of the most abundant sulfide mineral, $\mathrm{FeS}_{2}$ with anaerobic marine phototrophic microorganisms. Several theories have been developed following the discoveries of ocean-floor hydrothermal systems 
generating large volumes of sulfide minerals and associated with novel life forms and ecosystems.

Fig. 7 shows the Raman and FTIR spectrum of whole ore mineral containing $\mathrm{FeS}_{2}$ in a period of one week of interaction(s) with Erythrobacter Longus. In panel A, the in-tense Raman bands at 344 and 380 and $430 \mathrm{~cm}^{-1}$ originate from $\mathrm{FeS}_{2}$. More specifically, the $380 \mathrm{~cm}^{-1}$ band originates from the $\mathrm{Ag}$ in plane stretch $\mathrm{S}-\mathrm{S}$, the $344 \mathrm{~cm}^{-1}$ from the $\mathrm{S}-\mathrm{S}$ out of phase $E_{\mathrm{g}}$ mode and the 430 which has been assigned to $T_{\mathrm{g}}$ coupled libration and stretch mode. The full agreement of the Raman bands of the whole ore $\mathrm{FeS}_{2}$ with those reports from pure $\mathrm{FeS}_{2}$ samples demonstrates the reliability of the Raman spectroscopy in the characterization of whole ore minerals.

In Fig. 7, panel B, The FTIR spectrum of E. Longus (spectrum A) and the $50 \times 50 \mu \mathrm{m}$ FTIR imaging spectrum of $E$. Longus over the one week period of interaction with the $\mathrm{FeS}_{2}$ surface (spectrum B). The FTIR spectrum of E. Longus is characteristic of the bands at 1639 and $1554 \mathrm{~cm}^{-1}$ which are assign to the amide I and amide II, respectively. There are additional bands in the 1420 and $1100 \mathrm{~cm}^{-1}$ range due to $\mathrm{NH}_{4}^{+}$and carbohydrates,
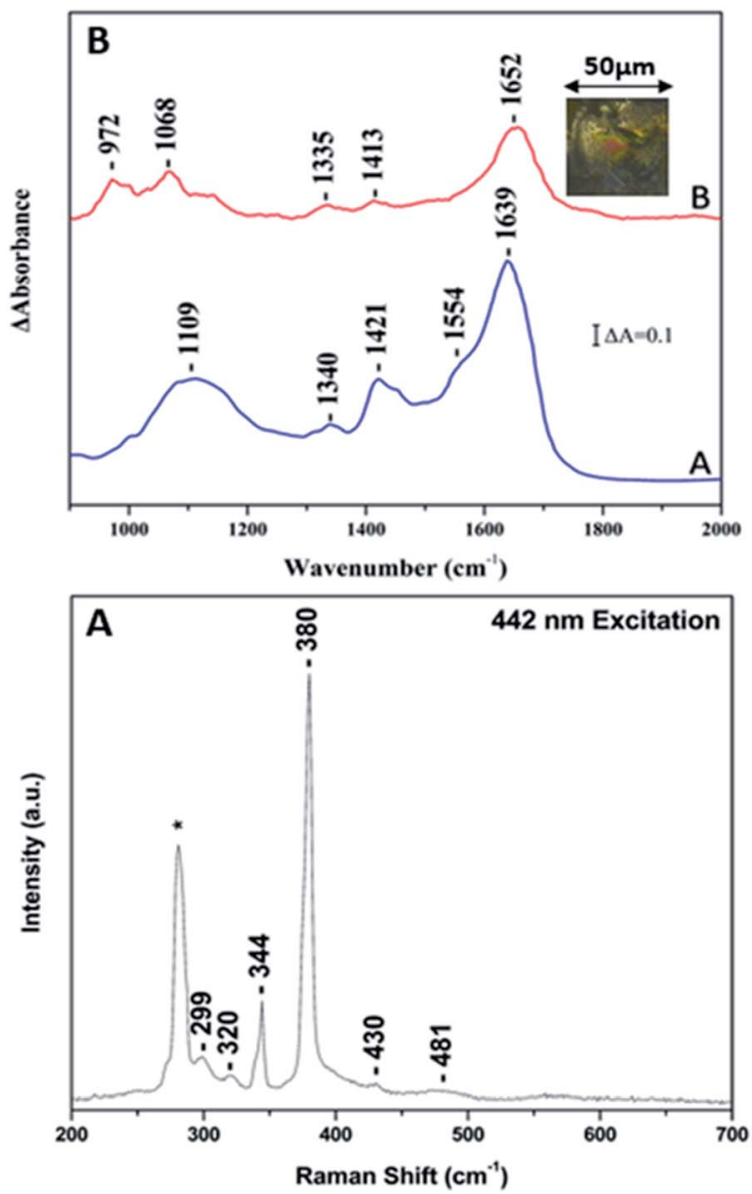

Fig. 7 Panel A: $442 \mathrm{~nm}$ Raman excitation spectra of the $\mathrm{FeS}_{2}$ in the presence of Erythrobacter Longus. The laser power incident on the sample was $20 \mathrm{~mW}$ and the accumulation time was 15 minutes. Panel B: collective image of Erythrobacter Longus (spectrum A) and of the surface of the $\mathrm{FeS}_{2}-E$. Longus complex. The area of infrared fingerprint is $0.005 \mathrm{~mm}^{2}$ with spectra resolution $4 \mathrm{~cm}^{-1}$. respectively. The well separated bands at 978, 1021 and $1051 \mathrm{~cm}^{-1}$ are due to carbohydrates and at $1134 \mathrm{~cm}^{-1}$ due to $\mathrm{P}=\mathrm{O}$. In spectrum $\mathrm{B}$ the appearance of band in the 970$1070 \mathrm{~cm}^{-1}$ indicates the presence of EPS biofilm formation. In addition, the am-ide II vibration has lost its intensity and the amide I vibration is up-shifted by $13 \mathrm{~cm}^{-1}$ indicating that the proteins of the EPS-FeS ${ }_{2}$ complex are involved in the EPS adsorption on $\mathrm{FeS}_{2}$.

LIBS is a relatively simple spectroscopic technique with various advantages that has been applied in a number of experiments and provide sustained, in situ, elemental detection in real time. ${ }^{57-62}$ In addition of having the ability to rapidly analyse the elemental composition of solids, liquids, and gases with little or no sample preparation, LIBS is one of the few techniques capable of non-contact and remote elemental analysis, making it particularly useful for analyses in extreme and hostile environments. The application of single pulse LIBS and development of dual-pulse LIBS (DP-LIBS) and resonanceenhanced LIBS for decreasing the limit of detection and improving reproducibility of LIBS in agricultural soil and
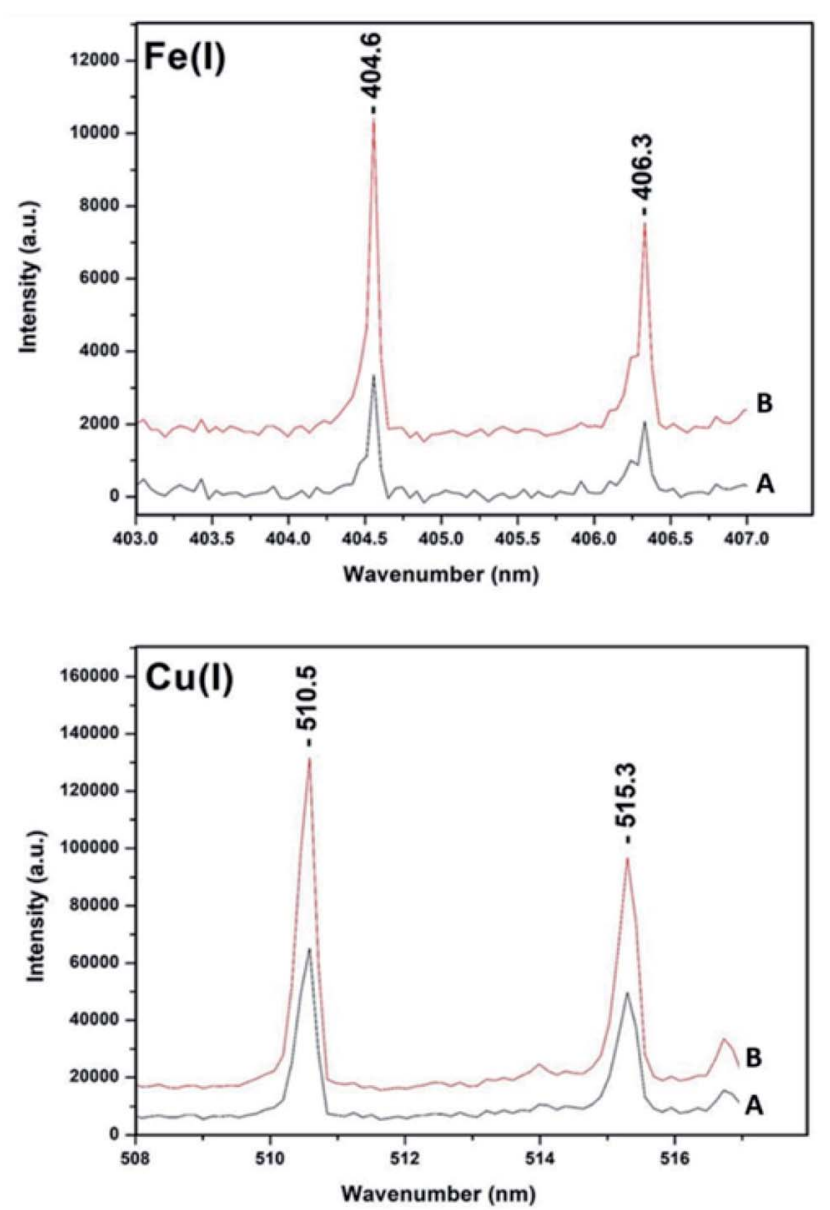

Fig. 8 Comparison of single pulse (spectrum A, $1064 \mathrm{~nm}$ ) with the collinear DP-LIBS (spectrum B, 532-1064 nm) signal intensity for natural $\mathrm{Cu}$ and Fe species. The $\mathrm{Cu} I$ lines are located at $510.5 \mathrm{~nm}$ and $521.8 \mathrm{~nm}$ and those of $\mathrm{Fe}(\mathrm{I})$ at $404.6 \mathrm{~nm}$ and $406.3 \mathrm{~nm}$. 
nutrients has been applied towards establishing new methods for improving the detection limit. ${ }^{61,62}$

Fig. 8 shows large enhancement in LIBS signals for 532$1064 \mathrm{~nm}$ combination in collinear arrangement. For all the comparisons the $1064 \mathrm{~nm}$ pulse energy and the in-ternal gate delay kept constant. The spot size for the $1064 \mathrm{~nm}$ was approximately 120 micrometers while for the $532 \mathrm{~nm}$ was 0.5 $\mathrm{mm}$. The time-delay between the two laser pulses was approximately $t_{\mathrm{d}}=1-2 \mathrm{~ns}$. It can be clearly seen that there is enhancement in signal intensity for the collinear DP-LIBS. For all measurements a fixed gate delay and $t_{\mathrm{d}}$ was used. It remains to be established whether the intensity signals depend on the gate delay and $t_{\mathrm{d}}$. Several mechanisms have been reported suggesting that the increase is due to either the increase in mass ablation or reheating of the plasma plume. The mass ablation rate depends on the wavelength because the shorter wavelength provides stronger laser-target coupling due to higher critical density $\left(n_{\mathrm{c}} \alpha 1 / \lambda^{-2}\right)$.

We have extended the single and DP-LIBS approaches and applied two additional LIBS methods using the same experimental set-up. In the third approach we have used the $532 \mathrm{~nm}$ pulse as a pre-pulse to generate the plasma prior to the use of the $1064 \mathrm{~nm}$ pulse for recording the LIBS and in the fourth approach in a similar configuration but using the $1064 \mathrm{~nm}$ for the pre-pulse and subsequently the $1064 \mathrm{~nm}$ for recording the LIBS. We have applied the four-way approach to $\mathrm{Cu} / \mathrm{Fe} / \mathrm{S}$ containing ores including chalcopyrite and idaite whole ore samples. There is a sequential signal increase in going from the

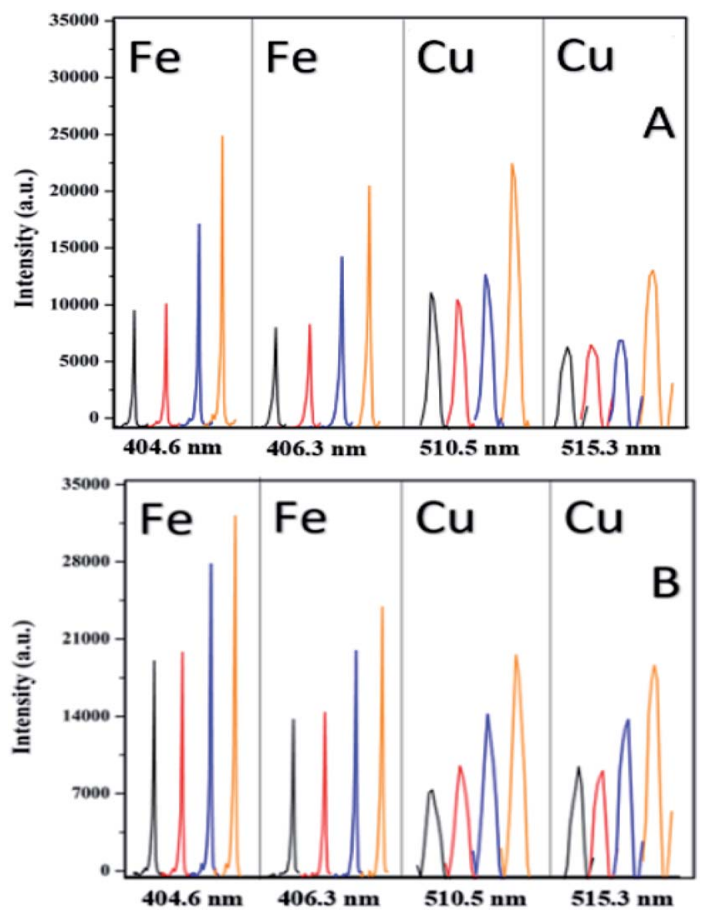

Fig. 9 Single $1064 \mathrm{~nm}$ LIBS (black), $532 \mathrm{~nm}$ prepulse to $1064 \mathrm{~nm}$ LIBS (red), $1064 \mathrm{~nm}$ prepulse to $1064 \mathrm{~nm}$ LIBS (blue) and 532-1064 nm with $t_{\mathrm{d}}=1-2 \mathrm{~ns}$ an internal pulse delay 2.41 microseconds DP-LIBS (orange) of chalcopyrite and idaite. The samples are the same used in the Raman and FTIR experiments. single pulse (1064 nm, black line) to prepulse-LIBS (532$1064 \mathrm{~nm}$, red line) to prepulse-LIBS(1064-1064 nm, blue line) and finally to collinear DP (532-1064 nm, orange line) (Fig. 9).

It is shown that this approach can achieve typical double pulse improvement in the analytical performances for elemental analysis chalcopyrite containing ores. The results show a significant increase of the intensity and repeatability of the emission signals in the double pulse configuration of both $\mathrm{Fe}$ and $\mathrm{Cu}$ contents in the chalcopyrite ore. The improvement resulting from the use of DP-LIBS was about $100 \%$ when compared to SP-LIBS in all cases. These results are useful in the context of studies investigating how the $\mu$-LIBS will assist in the development of portable LIBS systems and improve the utility of this spectroscopy technique for field applications. ${ }^{63-68}$

\section{Conclusions}

The combination of LIBS with $\mu$-FTIR and $\mu$-Raman provides a unique opportunity to probe the content of whole ore minerals, to characterize the minerals and their interactions with microorganisms. The FTIR mapping experiments provide information related to the adsorption induced variation on the bioleached ores. The present work extends our previous investigations of the $\mathrm{Cu} / \mathrm{Fe} / \mathrm{S}$ containing minerals and indicate that similar approaches are feasible for any type of metal containing minerals. It should be noted that the application of single LIBS it is much easier than the DP-LIBS and it is not absolutely necessary to double the signal intensity to identify the minerals.

Time-resolved Raman and TR- FTIR spectroscopies have been applied extensively in the past for the investigation of biochemical mechanisms of nitric oxide and dioxygen respiration by cytochrome oxidases, nitric oxide reductases and the interactions of microorganisms with surfaces and metals in our laboratory. ${ }^{22-35,69-71}$ The present work extends our previous investigation and the detailed analysis of the data obtained with all three techniques demonstrates the necessity for their concurrent ap-plication towards the elucidation of complex systems such whole ore minerals.

\section{Conflicts of interest}

There are no conflicts to declare.

\section{Acknowledgements}

Financial support by the European Regional Development Fund and the Republic of Cyprus through the Research Promotion Foundation (Grant No. ENTERPRISES/0916/0069) is gratefully acknowledged.

\section{Notes and references}

1 L. Jiang, H. Zhou and X. Peng, Chin. Sci. Bull., 2007, 52(19), 2702-2714.

2 H. Zhao, J. Wang, X. Gan, X. Zheng, L. Tao, M. Hu, Y. Li, W. Qin and G. Qiu, Bioresour. Technol., 2015, 194, 28-35. 
3 A. Adamou, G. Manos, N. Messios, L. Georgiou, C. Xydas and C. Varotsis, Bioresour. Technol., 2016, 214, 852-855.

4 A. Adamou, A. Nicolaides and C. Varotsis, Miner. Eng., 2019, 132, 39-47.

5 L. Di Giambattista, P. Grimaldi, I. Udroiu, D. Pozzi, G. Cinque, A. Giansanti and A. Congiu Castellano, FTIR Spectral Imaging as a Probe of Ultrasound Effect on Cells in Vitro, Biophys. Bioeng. Lett., 2009, 2, 22-34.

6 Y. Schmitt, H. Hähl, C. Gilow, H. Mantz, K. Jacobs, O. Leidinger, M. Bellion and L. Santen, Biofilms: Simulations and Experiments, Biomicrofluidics, 2010, 4(3), 32201.

7 L. A. Mutch, H. R. Watling and E. L. J. Watkin, Microbial, Hydrometallurgy, 2010, 104(3-4), 391-398.

8 Y. Yang, S. N. Tan, A. M. Glenn, S. Harmer, S. Bhargava and M. Chen, Biofouling, 2015, 31(7), 575-586.

9 M. Vera, B. Krok, S. Bellenberg, W. Sand and A. Poetsch, Proteomics, 2013, 13(7), 1133-1144.

10 M. Diao, E. Taran, S. Mahler, A. V. Nguyen and A. Concise, Adv. Colloid Interface Sci., 2014, 212, 45-63.

11 Y. Cao, X. Wei, P. Cai, Q. Huang, X. Rong and W. Liang, Colloids Surf., B, 2011, 12-18.

12 L. Fang, Y. Cao, Q. Huang, S. Walker and P. Cai, Water Res., 2012, 46, 5613-5620.

13 S. S. Feng, H. Yang and W. Wang, Bioresour. Technol., 2015, 192, 75-82.

14 S. S. Feng, Y. Xin, H. I. Yang, I. Zhang, W. L. Kang, X. L. Xia and W. Wang, J. Ind. Microbiol. Biotechnol., 2012, 39, 11611168.

15 S. S. Feng, H. I. Yang, Y. Xin, I. Zhang, W. L. Kang and W. Wang, J. Ind. Microbiol. Biotechnol., 2012, 39, 1625-1635.

16 T. Gehrke, J. Telegdi, D. Thierry and W. Sand, Appl. Environ. Microbiol., 1998, 64, 2743-2747.

17 Y. Jiao, G. D. Cody, A. K. Harding, P. Wilmes, M. Schrenk, K. E. Wheeler, J. Banfield and M. P. Thelen, Appl. Environ. Microbiol., 2010, 76, 2916-2922.

18 G. K. Parker, G. A. Hope and R. Woods, Colloids Surf., A, 2008, 325, 132-140.

19 M. Rivas, M. Seeger, E. Jedlicki and D. S. Holmes, Appl. Environ. Microbiol., 2007, 73, 3225-3231.

20 W. Sand and T. Gehrke, Res. Microbiol., 2006, 157, 49-56.

21 K. Sasaki, T. Nakamuta, T. Hirajima and O. H. Tuovinen, Hydrometallurgy, 2009, 95, 153-158.

22 K. Sasaki and H. Konno, Can. Mineral., 2000, 38, 45-56.

23 J. Sheals, S. Sjoberg and P. Persson, Environ. Sci. Technol., 2002, 36, 3090-3095.

24 J. M. Tapia, J. Munoz, F. Gonzalez, M. L. Blazquez and A. Ballester, Prep. Biochem. Biotechnol., 2013, 43, 815-827.

25 H. R. Watling, Hydrometallurgy, 2006, 84, 81-108.

26 H. Zhao, X. Gan, J. Wang, L. Tao, W. Qin and G. Qiu, Hydrometallurgy, 2017, 171, 374-386.

27 Y. Li, N. Kawashima, J. Li, A. P. Chandra and A. R. Gerson, Adv. Colloid Interface Sci., 2013, 197-198, 1-32.

28 C.-J. Africa, R. P. van Hille and S. T. L. Harrison, Appl. Microbiol. Biotechnol., 2013, 97(3), 1317-1324.

29 H. R. Watling, Hydrometallurgy, 2006, 84(1-2), 81-108.
30 S. Feng, Y. Xin, H. Yang, L. Zhang, W. Kang, X. Xia, et al, J. Ind. Microbiol. Biotechnol., 2012, 39(8), 1161-1168.

31 S. Feng, H. Yang, Y. Xin, L. Zhang, W. Kang and W. Wang, J. Ind. Microbiol. Biotechnol., 2012, 39(11), 1625-1635.

32 S. Feng, H. Yang and W. Wang, Bioresour. Technol., 2015, 192, 75-82.

33 H. Zhao, J. Wang, X. Gan, X. Zheng, L. Tao, M. Hu, et al, Bioresour. Technol., 2015, 194, 28-35.

34 K. Sasaki, Y. Nakamuta, T. Hirajima and O. H. Tuovinen, Hydrometallurgy, 2009, 95(1-2), 153-158.

35 C. Varotsis, M. Papageorgiou, C. Tselios, K. A. Yiannakkos, A. Adamou and A. Nicolaides, Aspects in Mining \& Mineral Science, 2020, 5(1), 000603.

36 T. Gehrke, J. Telegdi, D. Thierry and W. Sand, Appl. Environ. Microbiol., 1998, 64(7), 2743-2747.

37 J. M. Tapia, J. Muñoz, F. González, M. L. Blázquez and A. Ballester, Prep. Biochem. Biotechnol., 2013, 43(8), 815-827.

38 Y. Huang, Y. Zhang, H. Zhao, Y. Zhang, Y. Xiong, L. Zhang, et al., Int. J. Electrochem. Sci., 2017, 1211(10), 10493-10510.

39 G. K. Parker, G. A. Hope and R. Woods, Colloids Surf., A, 2008, 325(3), 132-140.

40 G. Consrnntinou, Am. Mineral., 1975, 60, 3.

41 K. Sasaki and H. Konno, Can. Mineral., 2000, 38, 45-56.

42 M. Rivas, M. Seeger, E. Jedlicki and D. S. Holmes, Appl. Environ. Microbiol., 2007, 73(10), 3225-3231.

43 L. Fang, Y. Cao, Q. Huang, S. L. Walker and P. Cai, Water Research, 2012, 46(17), 5613-5620.

44 Y. Cao, X. Wei, P. Cai, Q. Huang, X. Rong and W. Liang, Colloids Surf., B, 2011, 83(1), 122-127.

45 Y. Jiao, G. D. Cody, A. K. Harding, P. Wilmes, M. Schrenk, K. E. Wheeler, et al., Appl. Environ. Microbiol., 2010, 76(9), 2916-2922.

46 K. Sasaki, T. Sakimoto, M. Endo and H. Konno, Mater. Trans., 2006, 47(4), 1155-1162.

47 C. Varotsis, M. Papageorgiou, C. Tselios, K. A. Yiannakkos, C. Andreou, A. Adamou and A. Nicolaides, Crystals, 2020, 10, 1002.

48 H. Zhao, J. Wang, X. Gan, X. Zheng, L. Tao, M. Hu, Y. Li, W. Qin and G. Qiu, Bioresour. Technol., 2015, 194, 28-35.

49 C. J. Africa, R. P. van Hille and S. T. L. Harrison, Appl. Microbiol. Biotechnol., 2013, 97, 1317-1324.

50 M. Papageorgiou, C. Tselios and C. Varotsis, RSC Adv., 2019, 9(47), 27391-27398.

51 C. Tselios, M. Papageorgiou and C. Varotsis, RSC Adv., 2019, 9(33), 19121-19125.

52 C. Koutsoupakis, T. Soulimane and C. Varotsis, J. Biol. Chem., 2003, 278(38), 36806-36809.

53 S. Stavrakis, E. Pinakoulaki, A. Urbani and C. Varotsis, J. Phys. Chem. B, 2002, 106(50), 12860-12862.

54 E. Pinakoulaki and C. Varotsis, J. Inorg. Biochem., 2008, 102(5-6), 1277-1287.

55 E. Pinakoulaki and C. Varotsis, Biochemistry, 2003, 42(50), 14856-14861.

56 C. Varotsis and M. Vamvouka, J. Phys. Chem. B, 1999, 103(19), 3942-3946.

57 A. E. Majd, A. S. Arabanian and R. Massudi, Opt. Lasers Eng., 2010, 48, 750-753. 
58 P. K. Diwakar, S. S. Harilal, J. R. Freeman and A. H. Hassanein, Spectrochim. Acta, Part B, 2013, 87, 65-73. 59 Q. Lin, et al., Appl. Spectrosc. Rev., 2013, 48, 6487-508.

60 S. K. Sharma, A. K. Misra, P. G. Lucey, R. C. Wiens and S. M. Clegg, Spectrochim. Acta, Part A, 2007, 68, 1036-1045.

61 V. I. Babushok, et al., Spectrochim. Acta, Part B, 2006, 61(9), 999-1014.

62 E. Tognoni and G. Cristoforetti, J. Anal. At. Spectrom., 2014, 29(8), 1318-1338.

63 I. Y. Elnasharty, F. R. Doucet, J. F. Y. Gravel, P. Bouchard and M. Sabsabi, Double-pulse LIBS combining short and long nanosecond pulses in the microjoule range, J. Anal. At. Spectrom., 2014, 29, 1660-1666.

64 S. Li, L. Liu, A. Yan, S. Huang, X. Huang, R. Chen, Y. Lu and K. Chen, A compact field-portable double-pulse laser system to enhance laser induced breakdown spectroscopy, Rev. Sci. Instrum., 2017, 88, 023109.
65 P. Skrodzki, J. R. Becker, P. K. Diwakar, S. S. Harilal and A. Hassanein, A Comparative Study of Single-pulse and Double-pulse Laser-Induced Breakdown Spectroscopy with Uranium-containing Samples, Appl. Spectrosc., 2016, 70, 467-473.

66 K. Rafai, et al., Minerals, 2020, 10, 207.

67 K. Rafai, et al., Minerals, 2020, 10, 918.

68 N. Mohamed, et al., Geostand. Geoanal. Res., 2021, 45, 539.

69 C. Koutsoupakis, E. Pinakoulaki, S. Stavrakis, V. Daskalakis, C. Varotsis Biochimica, et al., Biochim. Biophys. Acta, Biomembr., 2004, 1655, 347-352.

70 E. Pinakoulaki, H. Yoshimura, S. Yoshioka, S. Aono and C. Varotsis, Biochemistry, 2006, 45(25), 7763-7766.

71 M. Papageorgiou, C. Tselios and C. Varotsis, J. Photochem. Photobiol., B, 2020, 213, 11206. 